\title{
A Survey on the Associated Factors of Stress among Operating Room Personnel
}

\author{
Yosra Azizpour ${ }^{1}$, Masoumeh Shohani ${ }^{2,3,{ }^{*}}$, Kourosh Sayehmiri ${ }^{4}$, Sattar Kikhavani $^{5}$ \\ ${ }^{1}$ Student Research Committee, Ilam University of Medical Sciences, Ilam, IR Iran \\ 2 Student Research Committee, Ilam University of Medical Sciences, Ilam, IR Iran \\ 3 Ptudent Research Committee, Tabriz University of Medical Sciences, Tabrical \\ 4 Department of Biostatistics, Research Centre for Prevention of Psychosocial Trauma, Ilam University of Medical Sciences, Ilam, IR Iran \\ 5 Department of Clinical Psychology, Ilam University of Medical Sciences, Ilam, IR Iran \\ ${ }^{*}$ Corresponding author: Masoumeh Shohani, Student Research Committee, Tabriz University of Medical Sciences, Tabriz, IR Iran; Paramedical School, Ilam University of Medical Sciences, \\ Pazhouhesh street, Ilam, IR Iran. Tel: +98-9188426498, Fax:+98-8412227134, E-mail:msh282000@yahoo.com.
}

Received: December 08, 2012; Revised: January 10, 2013; Accepted: January 26, 2013

\begin{abstract}
Background:Experiencing stress can notoriously affect people's mental and physical health. A major source of stress can be the workplace environment. According to the numerous studies, job stress among nurses is relatively higher than that of the other jobs.

Objectives: The aim of this study was examination of the relation between workplace environment and stress among operating room personnel in the training hospitals of Ilam University of Medical Science (IUMS).

Materials and Methods: This cross-sectional study was performed on all personnel of operating rooms (operating room technicians, anesthesia technicians and nurses) in training hospitals of IUMS. Fifty subjects were selected by sequential sampling. To collect data, demographic data and job stress questionnaires (Cooper) were used. Data were analyzed by descriptive and inferential statistics tests such as Chi-square, Pearson correlation coefficient, ANOVA and T-test.

Results: Higher levels of stress were due to the fear of being infected by HIV and hepatitis patients with mean of 3.2 and $58 \%$; and lack of weekends with mean of 3 and $44 \%$. The lowest levels of stress were related to inadequate skills with mean of 2.18 and $32 \%$, and environment light with mean of 2.14 and $34.7 \%$. Stress was significantly related to job status, conflict of doctors and nurses as well as spouses' attitude about work $(\mathrm{P}<0.05)$. But there was no significant relation between stress and work shift, age, being experienced, type of hospital and marital status.

Conclusions: According to the pivotal role of environmental and mental factors in the emergence of stress among operating room personnel, several considerations such as increasing the level of knowledge regarding infections, providing adequate resting time and improvement of the communications should be given among operating room personnel.
\end{abstract}

Keywords: Stress; Personnel; Operating Rooms

\section{Background}

Stress is referred to a pressure that may disrupt the balance of the living system and organism (1). It arises when there is inconsistency between the one's understanding of needs and his/her abilities to meet such needs (2). Stressors are factors that can affect people's mental and physical health and consequently disturb their normal function (3). Gastrointestinal disorders, headache, dizziness and severe fatigue are among side-effects and complications of stress $(4,5)$. Among the many different types of stress, the stress attributed to workplace environment is the most common by means of which persons go through mental and physical pressures and may fail to achieve their career goals (6). Also, job stress arises when the requirements of a certain job are far more than one's capabilities; consequently, people may undergo unpleasant and obnoxious emotional and physical reactions (7).
US National Association of Professional Safety indicated that among 40 professions, nursing has the highest level of stress (5). In their study, Enger Mayer et al. concluded that nursing, compared to other professions, is more subjected to stress (8). In addition to mental and physical disorders, it leads to such aberrations as absence from work, burnout, and developing problems for their family and patients $(8,9)(10)$. Studies indicated various levels of stress among nursing personnel, ranging from $54.1 \%$ to $90 \%(11,12)$.

The operating room is a complex, stressful and potentially hazardous environment. Risks have to do with patients' condition, competence of the surgeon to perform difficult procedures, team dynamics and organizational and environmental conditions (13). In addition, work pressures can result in decreased patient safety (14). This has been confirmed in a study by Elfering et al. that

Implication for health policy/practice/research/medical education:

According to the obtained results, there are different factors that induce stress in operating room personnel; accordingly, to reduce or remove the effects of stressors on occupational, individual and family behaviors and performances, concrete measures should be taken such as training the personnel about infectious diseases, providing adequate resting time and improvement of the communications.

Copyright (c) 2013, Kowsar corp. This is an Open Access article distributed under the terms of the Creative Commons Attribution License (http://creativecommons. org/licenses/by/3.0), which permits unrestricted use, distribution, and reproduction in any medium, provided the original work is properly cited. 
showed a direct correlation between stressful work situations and the patients safety (15). A review of over 300 empirical studies by Segerstrom and Miller) concluded that there is a direct correlation between workplace stress and the health of employees (16). Studies show that stressors present at operating rooms are of two types; stressors of the first type are mental stressors such as poor communication with team, and frequent and urgent need to decide, while stressors of the second type are physical environment factors such as light, moisture and structure of operating rooms (6). Other stressors are lack of job security, and variables such as working time, mortality of patients and possibility of providing wrong services to patients (17).

\section{Objectives}

Due to the importance of identifying stressors among the operating room personnel as well as inadequate studies in the field in Iran, this study was conducted to examine the relation between workplace environmental factors and stress among operating room personnel of IUMS training hospitals in 2012.

\section{Materials and Methods}

\subsection{Subjects}

This cross-sectional study was done among operating room personnel (operating room technicians, anesthesia technicians, and nurses) consisting of a total of 63 people. Of the 63 questionnaires distributed, 50 were completed. Study population was comprised of all the operating room personnel employed at the three training hospitals with different specialties of Ilam University of Medical Science (IUMS) with the following inclusion criteria: operating room technicians with associate degree and above, anesthesia technicians and nurses, with at least one year of work experience. They were all selected by sequential sampling. Subjects who did not wish to participate in the study, and subjects who had an irrelevant stressor outside the study environment were excluded.

\subsection{Data Collection Tools}

Data collection tools included two questionnaires. First questionnaire was developed by researchers and included physical environment and mental stressors and the second questionnaire was a Persian translation of the Cooper job stress test that was previously applied by researchers in other studies $(6,18-20)$. It included demographic variables too. Physical environment stressors included the structure and organization of the operating room, personnel equipment, working equipment, number of employees, level of moisture, heat, cold, light, unpleasant odors, chemicals, rays, fear of being infected
(HIV, hepatitis) and occupational hazard (such as contamination with secretions, blood and being injured by a needle). Mental stressors consisted of poor communication and collaboration with the team, bad planning, inadequate skills, urgent and frequent need to decide, and variables such as working time, lack of holidays, weekends and vacations. Questionnaires of physical environment and mental stressors included 20 questions in Likert scale with four options (never, sometimes, often, always) scoring from one to four. Demographic variables were age, gender, education, and marital status, work experience, working status, working shift and hospital workplace. Cooper standard questionnaire had 32 questions in Likert scale with four options (never, sometimes, often, always) scoring from one to four. Every subject answered the questions according to his/her corresponding level of stress. In this test, stressors were divided into four levels: lack of stress (> 32 scores), low stress (32 - 64 scores), moderate stress (64 - 96 scores) and severe stress $(<96$ scores) (21).

\subsection{Statistical Analysis}

Validity of the questionnaires was approved by experts in behavioral and psychological sciences. Reliability of the questionnaires was estimated $90 \%$ by Choronbakh's alpha coefficient. Data were analyzed by SPSS 16 using descriptive statistical methods (frequency, mean, standard deviation) and inferential statistics test (Chi-square, Pearson correlation coefficient, ANOVA and T-test). Subjects' consents were obtained and confidentiality of their data was maintained.

\section{Results}

Among the study population, majority of the subjects were female and married (68\%). Additionally, 22 - 32 year age group was the most frequent (52\%) age group of the study. The majority of operating room personnel had associate degree (66\%) and $56 \%$ of the subjects had $1-8$ years of work experience. Also, 50\% of the subjects were operating room technicians and all of them had variable working time. Among physical environment stressors of the operating room, light had the lowest effect on the level of stress (34.7\%) and the highest level of stress was related to fear of being infected by patients (58\%). Among mental stressors of the operating room, the lowest and the highest level of stressors pertained to inadequate skills (32\%) and lack of weekend and vacation time (44\%), respectively. Among all physical environment and mental stressors of the operating room, light (34.7\% and mean of 2.14 ), inadequate skills ( $32 \%$ and mean of 2.18 ) and fear of being infected (58\% and mean of 3.24) were of highest importance (Table 1). Results showed that the majority (66\%) of operating room personnel had low rates of stress (Figure 1). 
AzizpourYet al.

\begin{tabular}{|c|c|c|c|c|c|}
\hline $\begin{array}{l}\text { Stressful Factors, Physical Environment } \\
\text { and Mental }\end{array}$ & Never, No. (\%) & $\begin{array}{l}\text { Sometimes, } \\
\text { No. }(\%)\end{array}$ & Often, No. (\%) & $\begin{array}{l}\text { Always, No. } \\
(\%)\end{array}$ & $\begin{array}{l}\text { Total, No. } \\
\text { (\%) }\end{array}$ \\
\hline Operating Room Structure & $15(30)$ & $14(28)$ & $15(30)$ & $6(12)$ & $50(100)$ \\
\hline Equipment and Personnel Resources & $10(20)$ & $15(30)$ & $9(18)$ & $16(32)$ & $50(100)$ \\
\hline Working Equipment & $6(12.2)$ & $21(40.8)$ & $11(22.4)$ & $12(24.5)$ & $50(100)$ \\
\hline Number of Employees & $11(22)$ & $17(34)$ & $9(18)$ & $13(26)$ & $50(100)$ \\
\hline Moisture & $12(24.5)$ & $22(42.9)$ & $11(22)$ & $5(10.2)$ & $50(100)$ \\
\hline Heat & $9(18)$ & $14(28)$ & $16(32)$ & $11(22)$ & $50(100)$ \\
\hline Cold & $12(22.9)$ & $21(41.7)$ & $9(18.8)$ & $8(16.7)$ & $50(100)$ \\
\hline Light & $17(34.7)$ & $17(34.7)$ & $6(12.2)$ & $10(18.4)$ & $50(100)$ \\
\hline Unpleasant Odors & $3(6)$ & $15(30)$ & $9(18)$ & $23(46)$ & $50(100)$ \\
\hline Chemicals & $0(0)$ & $11(22)$ & $14(28)$ & $25(50)$ & $50(100)$ \\
\hline Rays & $4(8.2)$ & $9(18.4)$ & $12(24.5)$ & $25(49)$ & $50(100)$ \\
\hline Type of Work & $5(10.9)$ & $13(24.1)$ & $17(32.6)$ & $15(30.4)$ & $50(100)$ \\
\hline Fear of Being Infected (HIV, Hepatitis) & $2(4)$ & $13(26.1)$ & $6(12)$ & $29(58)$ & $50(100)$ \\
\hline Occupational Hazard & $3(6)$ & $13(26)$ & $10(20)$ & $24(48)$ & $50(100)$ \\
\hline $\begin{array}{l}\text { Poor Communication and Collaboration } \\
\text { with Team }\end{array}$ & $6(12)$ & $27(54)$ & $9(18)$ & $8(16)$ & $50(100)$ \\
\hline Bad Planning & $3(6.1)$ & $25(49)$ & $13(26.5)$ & $9(18.4)$ & $50(100)$ \\
\hline Inadequate Skills & $16(32)$ & $17(34)$ & $9(18)$ & $8(16)$ & $50(100)$ \\
\hline Urgent and Frequent Need to Decide & $11(22.4)$ & $23(44.9)$ & $9(18.4)$ & $7(14.3)$ & $50(100)$ \\
\hline Variable Working Time & $8(16)$ & $22(44)$ & $13(26)$ & $7(14)$ & $50(100)$ \\
\hline Lack of Weekends and Vacation Time & $4(8)$ & $14(28)$ & $10(20)$ & $22(44)$ & $50(100)$ \\
\hline
\end{tabular}

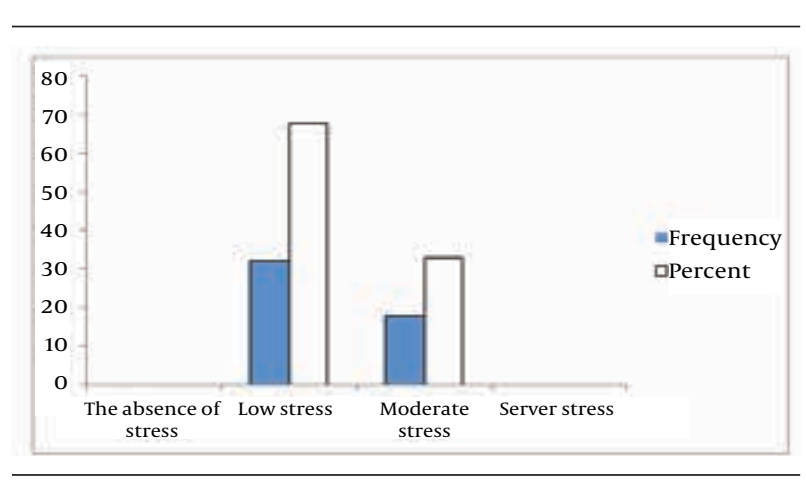

Figure 1. Professional Life Stress Test Scores

There was a significant difference between stress and work status among operating room technicians having the highest level of stress $(\mathrm{F}=4.793, \mathrm{P}=0.013)$. However, we did not detect any significant relation between gender, age, education, experience and marital status with stress (Table 2). Conflict with doctors and conflict with nurses were significantly related to spouses' attitudes toward work $(\mathrm{P}<0.05)$.

\section{Discussion}

This study showed that the majority of participants were experiencing a low level of stress, most likely because they were young, so they had adequate physical and mental fitness. Yao et al. reported that majority of nurses (72\%) experienced low rates of stress and a small group (23\%) had severe job-related stress (22). In the study of Schaefer and Moos which was performed on 405 ICU nurses, level of job stress was reported to be normal (23). Elamo et al. conducted a job stress study on 1320 nurses and demonstrated a higher rate of job stress in this group (24). Examining the effect of demographic variables indicated a significant relation between work status and stress; anesthesia technicians had more stress compared to other operating room personnel. Noteworthy, the work status stress is probably due to the technicians' critical job as any mistake can lead to serious complications and even death. Another study performed by Khodaveisi et al. showed that stress occurred among $70.4 \%$ of operating room personnel and among 8.7\% of ICU staff (25). Results of the study of Santa Maria and Sullivan conducted on 47 people showed that this group experienced higher stress rates (26). In the present research, a significant relation was detected between stress and the quality of the relationships nurses had with physicians and other colleagues. Conflict with colleagues can cause improper communication and collaboration and this in turn leads 
to a sense of diminished mental and social support received from colleagues (27).

\begin{tabular}{|c|c|c|}
\hline Demographic Variables & Mean \pm SD & Pvalue \\
\hline Age, $y$ & & 0.069 \\
\hline $22-32$ & $60.03 \pm 8.65$ & \\
\hline $32-42$ & $57.50 \pm 10.20$ & \\
\hline $42-52$ & $58.00 \pm 18.63$ & \\
\hline Gender & & 0.190 \\
\hline Female & $59.26 \pm 8.86$ & \\
\hline Male & $58 \pm 12.53$ & \\
\hline Education & & 0.242 \\
\hline Degree & $60.42 \pm 9.20$ & \\
\hline BA & $55.00 \pm 8.53$ & \\
\hline MA & $59.66 \pm 22.54$ & \\
\hline Position & & 0.013 \\
\hline Operating Room Technician & $62.96 \pm 10.74$ & \\
\hline Anesthesia Technician & $54.93 \pm 7.48$ & \\
\hline Nurse & $54.50 \pm 7.97$ & \\
\hline Shift, in Circulation & $58.86 \pm 10.06$ & 0.05 \\
\hline Hospital Work & & 0.833 \\
\hline Imam Khomeini & $58.29 \pm 10.32$ & \\
\hline Shahid Mostafa Khomeini & $59.94 \pm 10.33$ & \\
\hline Taleghani & $57.50 \pm 8.88$ & \\
\hline Experience, y & & 0.144 \\
\hline $1-8$ & $60.89 \pm 8.50$ & \\
\hline $10-19$ & $57.93 \pm 9.27$ & \\
\hline $20-30$ & $52.71 \pm 15.37$ & \\
\hline Marital Status & & 0.082 \\
\hline Single & $59.25 \pm 8.12$ & \\
\hline Married & $58.50 \pm 11.73$ & \\
\hline
\end{tabular}

The significant association between stress rate and the spouses' attitude toward work shows that if people do too much activity and spend too much energy, they may become more exhausted which may eventually lead to troubles among family members. A study performed by Mehrabi et al. on nurses showed that among job stressors, conflict with physicians caused highest rates of stress (28). Roberts et al. suggested that poor communication and collaboration with team was one of the job stressors in the nursing profession; also a large part of stress could come from inter-personnel relationships and job-related issues (29). The study conducted by Caregnato RC et al. performed on the interviews of 32 surgical team members suggested that inter-personnel relationship is one of the major stressors (30). According to findings of the present study, light had the lowest level of importance as a stressor in physical environment while the highest level of stress was attributed to the fear of being infected (HIV and hepatitis). Working in hospitals and clinics with poor physical standards and equipments such as light, heat, cold etc. may result in physical and mental problems for nurses (27). Results of a study by Fathi showed that light is one of the major sources of environmental stress in the ICU (31). Ahangarzadeh et al. also introduced inadequate light and limited space as physical environment stressors (18). Fear of being infected can result from occupational hazards such as contamination with secretions, blood and injury by a needle and syringe. Blegen et al. reported that taking care of the infected patients is one of the major sources of stress among nurses (32).

Among the mental stressors of operating room, inadequate skills and lack of weekend and vacation time were related to the lowest and highest levels of stress, respectively. The more nurses feel they have insufficient skills, the more they feel disqualified for the job and this in turn leads to stress. Michie et al. showed that skills being increased by nurses can reduce job stress (33). In the study by Khodayar on nurses, $48 \%$ of the personnel complained about work overload and lack of vacation (34). In the present study, there was no significant relation between age, gender, work record, educational degree, marital status and stress. Juthberg et al. showed that there is a negative and significant relation between age and stress (35). Also, Sherbafnejad suggested that a significant relation exists between age and job stress (36). However, the study of Shahraki Vahed demonstrated that there was no significant relation between nurses' ages and job stress (37). Also, a significant association was reported between experience and job stress in the study of Lee et al. among nurses (38). In the study performed by GhulamNejad on 140 nurses of various wards, a direct and significant correlation was reported between job stress and gender (39). In another prospective study conducted by Eriksen et al. on nurses a significant inverse correlation was found between work experience and stress (40). In the study by Asad Zandi on 272 nurses working in military hospitals, there was a significant association between stress and education level (41). In this study, the insignificant relation between such variables and stress may be due to the small sample size.

Findings of this study showed that the majority of subjects had low stress rates. Operating room technicians were experiencing higher rates of stress compared to the other operating room personnel. According to the obtained results, different factors may induce stress in operating room personnel. Accordingly, to reduce or remove the effects of stressors on occupational, individual and family behaviors and performances, several important steps such as training the personnel about infectious diseases, providing adequate resting time and vacation for the staff and improvement of the communications should be taken. 


\section{Acknowledgements}

Authors would like to thank the generous cooperation of all participants and their unfailing supports as well as the guidance received from professors of Ilam University of Medical Sciences.

\section{Authors' Contribution}

Yosra Azizpour:\%40; Masoumeh Shohani:\%40; Kourosh Sayehmiri:\%10; Sattar Kikhavani: \%10

\section{Financial Disclosure}

There is not any conflict of interest.

\section{Funding/Support}

This research was supported by Ilam University of Medical Sciences.

\section{References}

1. Maxine Ross S. Holistic Nursing Practice. Fredrich. 2008;22(6):365.

2. Clancy J, McVicar AJ. Physiology and Anatomy: A Homeostatic Approach. 2002

3. Ahmady S, Changiz T, Masiello I, Brommels M. Organizational role stress among medical school faculty members in Iran: dealing with role conflict. BMC Med Educ. 2007;7:14

4. Hamidi N. [Effects of stress on immune system students]. Jundishapur Sci Med J. 2003;37(2):12-14.

5. Simmons BL, Nelson DL. Eustress at work: the relationship between hope and health in hospital nurses. Health care manage Rev. 2001;26(4):7-18.

6. Kolakar SH, Sanakoo A, Mirkarime F, Behnampour N. The level of stress among Gorgan University of Medical Sciences hospital operation room's personals and its relation to some related factors. J Gorgan Univ Med Sci. 2002;4(2):54-59.

7. Merille K. Stress and How to beat it. J nurs stand. 2001;15(28):7-16.

8. Angermeyer MC, Bull N, Bernert S, Dietrich S, Kopf A. Burnout of caregivers: a comparison between partners of psychiatric patients and nurses. Arch psychiatr Nurs. 2006;20(4):158-65.

9. Currid TJ. The lived experience and meaning of stress in acute mental health nurses. BrJ Nurs. 2008;17(14):880-4.

10. Aghilinejad M, Attarchi MS, Golabadi M, Chehregosha H. Comparing stress level of woman nurses of different units of Iran university hospitals in autumn 2009. HBI J. 2010;8(1):44-48.

11. Rahimi A, Ahmadi F, Akhond MR. An investigation of amount and factors affecting nurses' job stress in some hospitals in Tehran. Hayat. 2004;10(22):13-22.

12. Khaghanizadeh M, Ebadi A, Cirati nair M, Rahmani M. The study of relationship between job stress and quality of work life of nurses in military hospitals. J Military Med. 2008;10(3):175-184.

13. Arora S, Sevdalis N, Nestel D, Tierney T, Woloshynowych M, Kneebone R. Managing intraoperative stress: what do surgeons want from a crisis training program? Am J Surg. 2009;197(4):537-43.

14. Carayon P, Gurses AP. A human factors engineering conceptual framework of nursing workload and patient safety in intensive care units. Intensive Crit Care Nurs. 2005;21(5):284-301.

15. Elfering A, Semmer NK, Grebner S. Work stress and patient safety: observer-rated work stressors as predictors of characteristics of safety-related events reported by young nurses. Ergonomics. 2006;49(5-6):457-69.

16. Segerstrom SC, Miller GE. Psychological stress and the human immune system: a meta-analytic study of 30 years of inquiry. Psychol Bull. 2004;130(4):601-30.

17. Heroabadi SH, Marbaghi A, 2nd ed . management in nursing and midwifery. 2007.

18. Ahangar-Zadeh Rezai S, Shams al-Din SH, saghi -zadeh M. Survey of job stressors and coping strategies on nurses in psychiatric and general centers in urmia. Bimonthly J Urmia Nurs Midwifery Faculty. 2008;6(1):50-67.

19. Zarea M, Abedi KA, Halvani GH, Barkhordari A, Amini-pour MR. Study of job stress in workers Ports and Shipping Organization Hormozgan and its relationship with non-fatal accidents occurred. Martyr sadoghi Yazd Univ Medl S. 2009;17(3):142-8.

20. Aghaii A, Jalali D. Effect of training group cognitive - behavioral on job stress Contacts Company employees. J Psychol Educ S ,Behav S. 1385;(5):21-8.

21. Cooper CL. Identifying stressors at work: recent research developments. J Psychosom Res. 1983;27(5):369-76.

22. Yao SQ, Tian L, Pang BD, Bai YP, Fan XY, Shen FH, et al. [Investigation on job stress of pediatricians and nurses working in pediatric department]. Zhonghua Lao Dong Wei Sheng Zhi Ye Bing Za Zhi. 2008;26(9):529-32.

23. Schaefer JA, Moos RH. Effects of work stressors and work climate on long-term care staff's job morale and functioning. Res Nurs Health. 1996;19(1):63-73.

24. Raiger J. Applying a cultural lens to the concept of burnout. J Transcult Nurs. 2005;16(1):71-6.

25. Khodaveisi M, Mohammadi N, Omidi A. Frequency of Job Stress in Clinical Nurses $\mathrm{n}$ the hospitals of Hamadan. J Nurs Midwifery, Hamedan. 2005;13(24):44-50.

26. Santamaria N, O'Sullivan S. Stress in perioperative nursing: sources, frequency and correlations to personality factors. Collegian.1998;5(3):10-5.

27. Ghasemi SA, Attar M. Survey of hospital nurses job stress factors in Babol, Sari and behshahr. 2008; Available from: www.betsa.ir.

28. Mehrabi T, Parvin N, Yazdani M, Rafat aseman N. Review of some occupational stressors in nurses. I Nurs Midwifery, esfahan. 2005;27:30-37.

29. Roberts R, Golding J, Towell T, Weinreb I. The effects of economic circumstances on British students' mental and physical health. $J$ Am Coll Health. 1999;48(3):103-9.

30. Caregnato RC, Lautert L. [The stress of the multiprofessional team in the operating room]. Rev Bras Enferm. 2005;58(5):545-50.

31. Fathi M. The nursing stressors in critical care unites of kordestan university of medical sciences. J Kordestan unive Med Sci health serv. 2004;7(4):53-61.

32. Belgen MA, Mueller CW. Nurses job satisfaction: a longitudinal analysis . Res Nurs Health.1987;10(4):227-37.

33. Michie S, Williams S. Reducing work related psychological il health and sickness absence: a systematic literature review. Occup Environ Med. 2003;60(1):3-9.

34. Khodayar F. Review of stress in nurses in the intensive care unit Icu, ccu. Manual Seminar nursing concepts and theories of Tabriz University of Medical Sciences. 1998. p. 100.

35. Juthberg C, Eriksson S, Norberg A, Sundin K. Perceptions of conscience, stress of conscience and burnout among nursing staff in residential elder care. J Adv Nurs. 2010;66(8):1708-18.

36. Sherbafnejad J, Lak -Dizaji S, Namdar H, Ghoja-Zadeh M, FrtashNaimi A. Job Stressors in Nursing. Nurs Tabriz Midwifery J. 2008;(10):26-30.

37. Vahed AS, Hamuleh MM, Sanchuli J. Assessment of the relationship between mental health and job stress among nurses. J Jahrom Univ Med S.;8.

38. Lee I, Wang HH. Perceived occupational stress and related factors in public health nurses.J nurs Res. 2002;10(4):253-60.

39. Ghulam-nejad H, Nik-payma N. The causes of stress in nurses. J Iran Occup Health. 2009;6(1):22-27.

40. Eriksen W, Tambs K, Knardahl S. Work factors and psychological distress in nurses' aides: a prospective cohort study. BMC Public Health. 2006;6:290.

41. Asad Zandi M, Sayari R, Ebadi A, Sanainasab H. Abundance of depression, anxiety and stress in militant Nurses. Journal of Military Medicine. 2011;13(2):103-108. 